\title{
Inversion of Uterus - Presenting as a Complication of Abortion
}

\author{
NAZNEEN BEGUM ${ }^{1}$, SHIKHA GANGULY², BEGUM ROKEYAANWER ${ }^{3}$, FERDOUSI ISLAM ${ }^{4}$
}

\section{Introduction :}

Acute puerperal uterine inversion is rare but potentially fatal obstetric emergency. When repositioning of the uterus is not immediate, excessive bleeding can cause haemodynamic instability and shock. Uterine inversion following abortion is an extremely rare incident.

\section{Case Report:}

A 16 year old unmarried girl was admitted into the department of obstetrics and gynaecology in January 2013 with something coming down per vagina with history of induced abortion 6 weeks ago . This abortion followed a sexual assault about 6 months ago. She did not consult with any health care provider after rape. She was unaware of pregnancy until 16 weeks. Then she consulted a local traditional birth attendant in November 2012 for termination of pregnancy. The local Dai gave her some drugs orally. Some product of conception was expelled out with pain in abdomen and per vaginal bleeding. When she started bleeding profusey, the TBA did evacuation and curettage . Again she developed excessive pervaginal bleeding a few days later and she went to a district hospital . There they found a mass protruding through the introitus and introduced it within vagina and referred her to Khulna Medical College Hospital on 18 December 2012. They tried to reposit it pervaginally but failed. Again she started to bleed profusely and was admitted to a district hospital on $18^{\text {th }}$ January 2013. There she got blood transfusion and after 10 days she was referred to $\mathrm{DMCH}$. On Examination she was severely anaemic . A broad, globular, reddish purple mass with irregular surface was found protruding through the introitus.

On digital rectal examination fundus of uterus could not be felt, a cup like depression was felt . A diagnosis of postabortion uterine inversion with severe anaemia was done.
Anemia was corrected by compatible blood transfusion .Uterus was repositioned by Haultain's operation. The abdomen was opened up by a
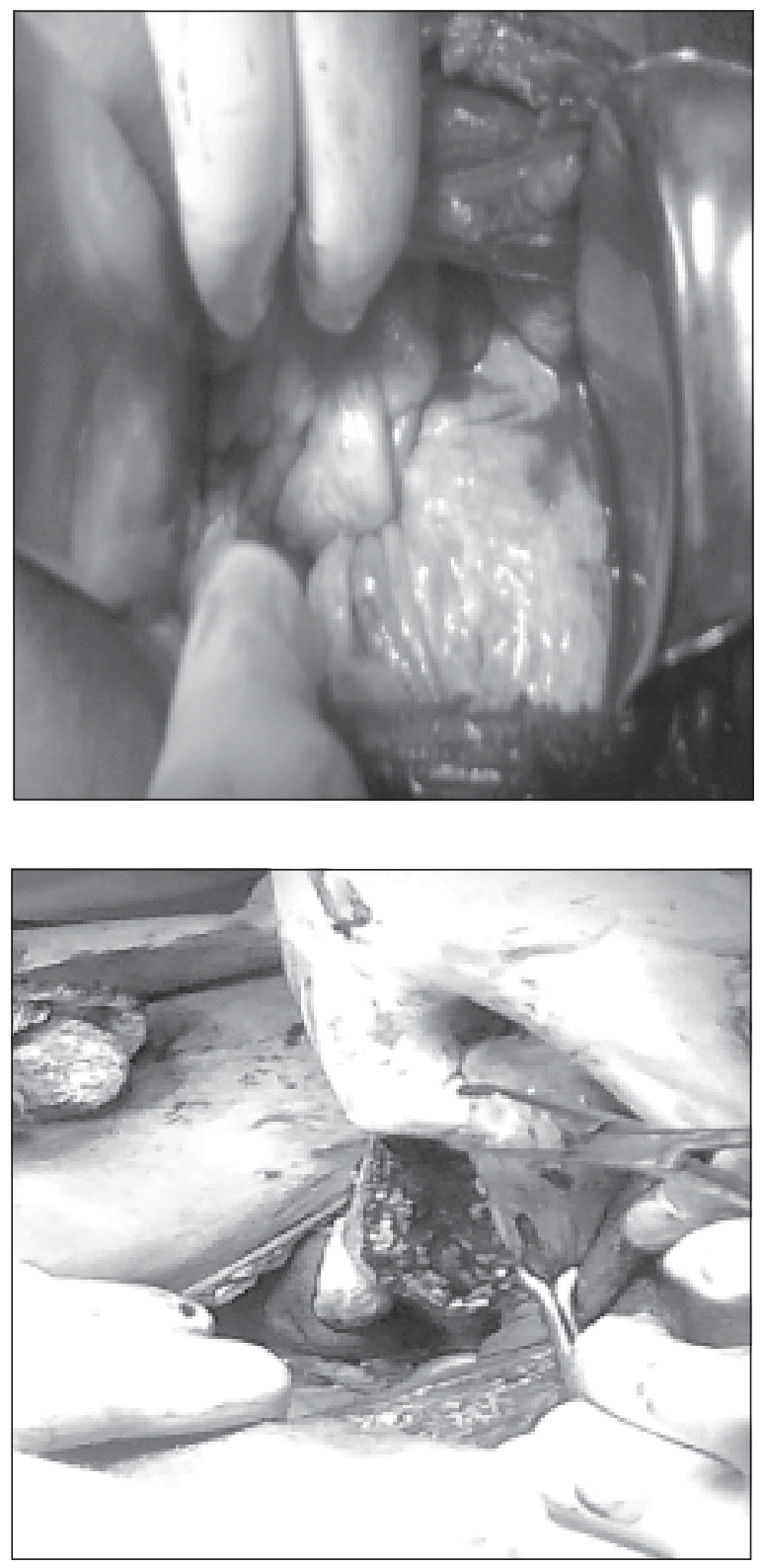

1. Assistant Professor, Dhaka Medical College

2. Associate Professor, Dhaka Medical College

3. Assistant Professor, Cancer Institute, Mohakhali, Dhaka

4. Professor \& Head of Department, Dhaka Medical College 
transverse incision and the pelvis was explored. In the region of the uterus a cup-shaped depression was noted. Tubes and ovaries of both sides were seen hanging laterally from the cupped area Uterus was pulled up by holding the posterior rim of cup by a volsellum . Posterior rim was incised longitudinally. A finger was passed through the incision into the vagina , then inverted fundus was pulled up . Uterine incision was repaired. The uterus was found to be bulky

Her postoperative period was uneventful. She came for postoperative follow up 6 week later and she resumed menstruation.

\section{Discussion:}

There are some reported cases of puerperal and nonpuerperal uterine inversions. The nonpuerperal cases are usually associated with presence of submucous myoma or sarcoma or growth within the uterine cavity .

Acute puerperal uterine inversion is a rare but potentially fatal obstetric emergency. A prompt recognition enables immediate repositioning of the uterus before it becomes edematous and incarcerated by a constriction ring which requires surgical intervention later on ${ }^{1}$.

Abortion related death has declined from 5\% of MMR in 2001 to about $1 \%$ of MMR in $2010^{2}$. Hemorrhage, perforation of uterus, sepsis, septic shock, pelvic abscess, perforation of bowel and bladder are the complications of abortion. But inversion of uterus is not a reported postabortal complication. This is described as a rare complication of puerperium ${ }^{3}$. It is a potentially life threatening condition and is associated with high maternal mortality in absence of early recognition and treatment in acute state ${ }^{4}$. In the case reported, etiology of inversion of the uterus following an abortion may be because of traction of placental tissue (which was adherent) by a traditional midwife. Repositioning of the uterus by Haultains method is the most popular method and rewarded with normal menstruation ${ }^{5}$, as seen in this case and even normal reproduction ${ }^{6}$. Uterine-sparing surgery should be the principal mode of treatment in young women.

\section{References:}

1. Sunitha, Vani Ramkumar. An unusual case of uterine inversion. Journal of Clinical and Diagnostic Research. 2011, Vol-5(3): 650-651

2. Bangladesh Maternal Mortality and Health Care 2010. 19

3. Marjolijn de Vries, Denise AM Perquin .Nonpuerperal uterine inversion due to submucous myoma in a young woman: a case report . Journal of Medical Case Reports 2010, 4:21 doi:10,1186/1752-1947-4-21

4. Hussain M, Jabeen T, Liaquat N, Noorani K, Bhutta SZ. Acute puerperal uterine inversion. J Coll Physicians Surg Pak2004;14(4):215-7

5. SE Adaji et al, Uterine inversion complicating traditional termination of pregnancy. Obstetrics and Gynaecology Forum. AJOL. Oct 2005;25-26.

6. Sinha $G$, Sinhan A. Fertility and reproduction following inversion of uterus. J Indian Med Assoc 1993; 91(6): 149-50. 